\section{UJMM

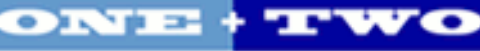

Volume 2 | 2010 Spring

\section{Undergraduate Journal of Mathematical}

Modeling: One + Two

2010

\title{
Finding the Area of an Irregularly Shaped Room
}

Justin Walls

University of South Florida

Advisors:

Arcadii Grinshpan, Mathematics and Statistics

Jack O'Neal, Plans by Design Company Owner

Problem Suggested By: Jack O'Neal

Follow this and additional works at: https://digitalcommons.usf.edu/ujmm

Part of the Mathematics Commons

UJMM is an open access journal, free to authors and readers, and relies on your support: Donate Now

\section{Recommended Citation}

Walls, Justin (2010) "Finding the Area of an Irregularly Shaped Room," Undergraduate Journal of Mathematical Modeling: One + Two: Vol. 2: Iss. 2, Article 12.

DOI: http://dx.doi.org/10.5038/2326-3652.2.2.12

Available at: https://digitalcommons.usf.edu/ujmm/vol2/iss2/12 


\title{
Finding the Area of an Irregularly Shaped Room
}

\author{
Abstract

\section{Keywords} \\ Area, Integration, Floor Plan \\ Creative Commons License \\ (c) (i) (9)
}

This experiment utilized integration in a practical sense by determining the floor area of an irregularly shaped room. By taking the integral summation of three sections formed from semi-circles, the desired areas as well as positive results were found. The final data determined that the floor area of the irregularly shaped room was around 580 square feet.

This work is licensed under a Creative Commons Attribution-Noncommercial-Share Alike 4.0 License. 


\section{TABLE OF CONTENTS}

Problem Statement. 3

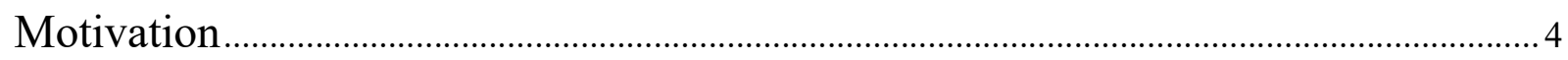

Mathematical Description and Solution Approach ……………………………………....4

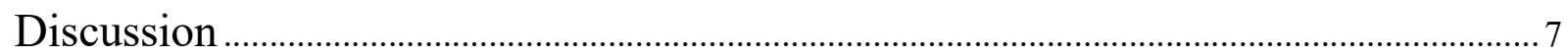

Conclusion and Recommendations........................................................................................

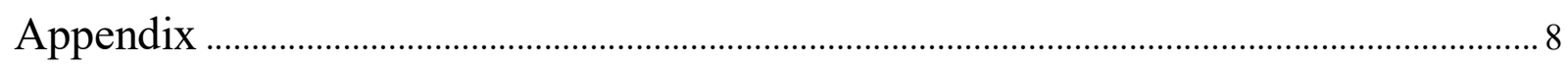




\section{PROBLEM STATEMENT}

Assuming a $4 \frac{1}{2}$ " thick wall, find the exact area of the room described from floor plan below (Figure 1) in order to determine how much material is needed to carpet the floor.

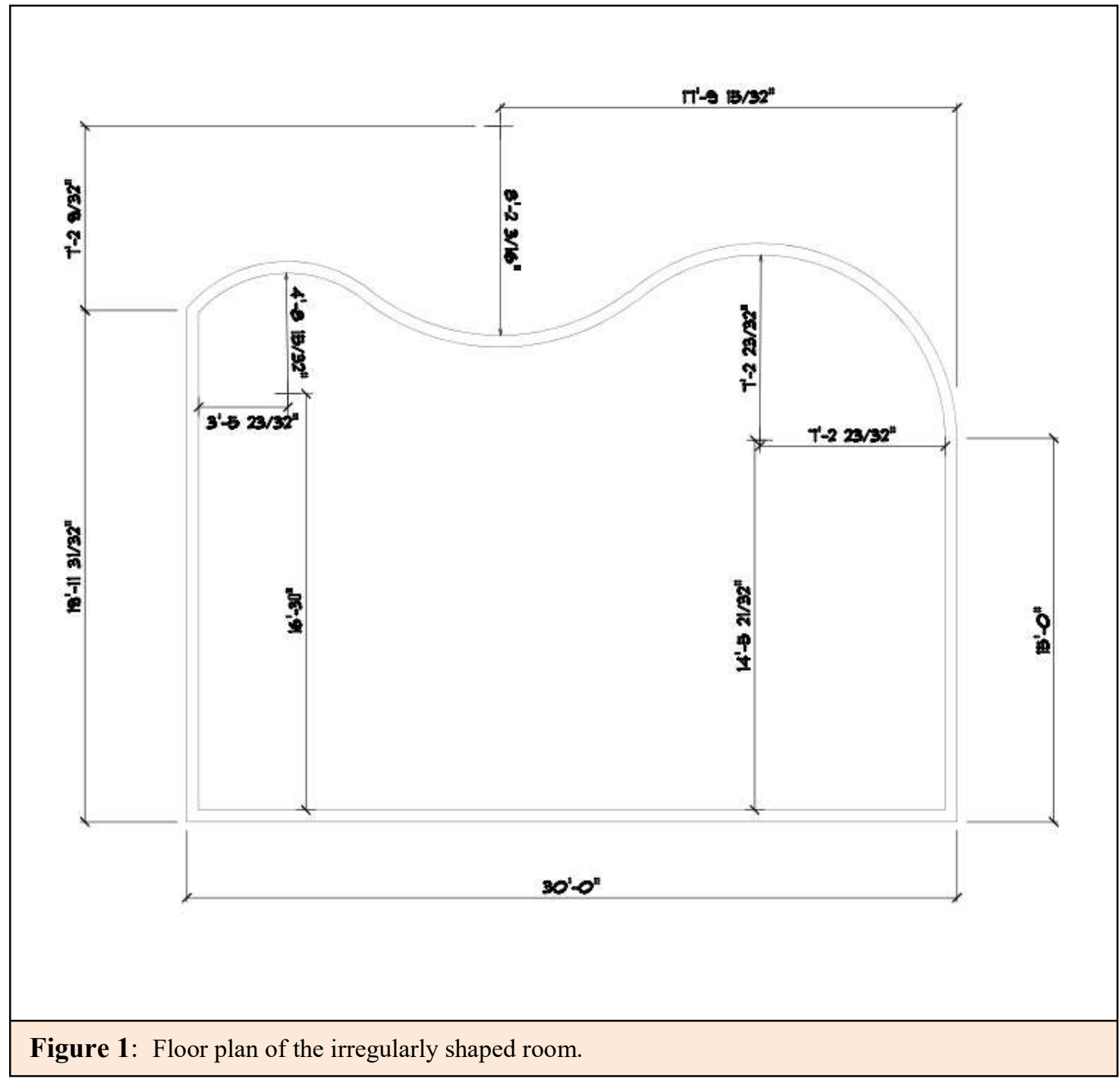




\section{MOTIVATION}

Calculating the footprint of a room is required to know how much material is needed to carpet the floor. By using integration to determine the area of irregularly shaped rooms, such as this one, a builder can choose the correct amount of materials and avoid both shortages and excesses. Such inefficiencies propagate over on multiple orders reducing overall profit. Engineers, in association with architects, can determine the exact square footage of a building by using calculus. This lets contractors know the precise amount of materials such as carpet, tile, or travertine which they need to purchase. Integration is the key to finding the area of rooms which are not designed using either elementary geometric shapes or a combination of simple shapes.

\section{MATHEMATICAL DESCRIPTION AND SOLUTION APPROACH}

The area of this room was determined by integrating three separate sections bounded by functions $f_{1}(x), f_{2}(x)$ and $f_{3}(x)$, i.e.

$$
\operatorname{Area}(\text { Room })=A=\int_{x_{0}}^{x_{1}} f_{1}(x) d x+\int_{x_{1}}^{x_{2}} f_{2}(x) d x+\int_{x_{2}}^{x_{3}} f_{3}(x) d x
$$

where the formulas describing each section were based on rectangles with a semi-circular ends (see Figure 2). Recall that the formula for a circle centered at $(h, k)$ with a radius $r$ is given by

$$
(x-h)^{2}+(y-k)^{2}=r^{2} .
$$

Expressing $y$ in terms of $x$ restricts the range of (1) from a circle to the upper semi-circle

$$
y=k+\sqrt{r^{2}-(x-h)^{2}}
$$


or the lower semi-circle

$$
y=k-\sqrt{r^{2}-(x-h)^{2}} .
$$

Thus, each function $f_{1}(x), f_{2}(x)$ and $f_{3}(x)$ was either of the form (3) or (4).

Let $x_{0}$ be the origin $(0,0)$. By comparing the dimensions in Figure 1 to the labels of Figure 2, we got the exact values for $x_{3}, c_{1}, r_{1}, c_{2}, r_{2}, c_{3}$, and $r_{3}$ (see Appendix). Note that $r_{2}$ is obtained by adding the wall thickness, $4 \frac{1 / 2}{2}$, to the radius of the outer wall and $x_{3}$ was obtained by subtracting the thickness of two walls from the total room width. These were the only two dimensions in the above list which were not explicitly given by the floor plan (Figure 1).

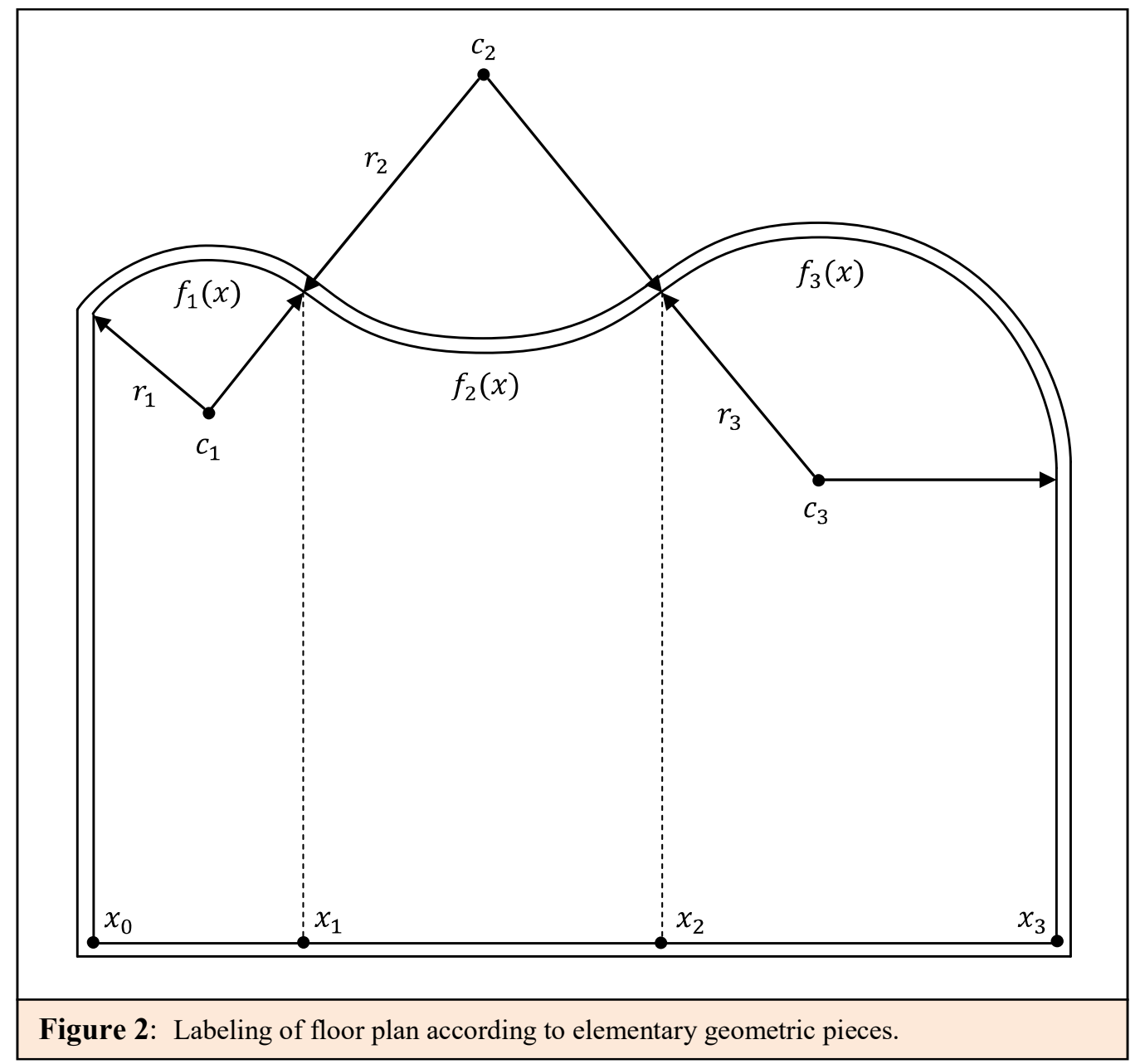


Clearly $f_{1}(x)$ is of type (3) which was defined precisely by the center $c_{1}=\left(h_{1}, k_{1}\right)$ and the radius $r_{1}$. Functions $f_{2}(x)$ and $f_{3}(x)$ are of type (4) and (3) respectively, and were similarly defined.

To find $x_{1}$ and $x_{2}$, the intersections of the semi-circular sections were found by equating the derivates of adjacent sections. See that

$$
f_{1}^{\prime}(x)=\frac{d}{d x}\left[k_{1}+\sqrt{r_{1}^{2}-\left(x-h_{1}\right)^{2}}\right]=\frac{h_{1}-x}{\sqrt{r_{1}^{2}-\left(x-h_{1}\right)^{2}}}
$$

and similarly

$$
f_{2}^{\prime}(x)=\frac{h_{2}-x}{\sqrt{r_{2}^{2}-\left(x-h_{2}\right)^{2}}}
$$

Equating (5) and (6) simplifies to

$$
x=\frac{h_{2} r_{1}+h_{1} r_{2}}{r_{1}+r_{2}} \approx 6.443
$$

and $x_{1}=(6.443,0.000)$. Likewise, equating $f_{2}^{\prime}(x)$ and $f_{3}^{\prime}(x)$ yields $x \approx 18.006$ and defines $x_{2}$.

Knowing the domain of each piece made it possible to characterize the three integrals which summed to the total area of the room. The integral for the first section was as follows:

$$
\begin{aligned}
A_{1} & =\int_{x_{0}}^{x_{1}}\left(k_{1}+\sqrt{r_{1}^{2}-\left(x-h_{1}\right)^{2}}\right) d x \\
& =k_{1}[x]_{x_{0}}^{x_{1}}+\left[\frac{1}{2}\left(h_{1}-x\right) \sqrt{r_{1}{ }^{2}-\left(x-h_{1}\right)^{2}}+r_{1}{ }^{2} \tan ^{-1}\left(\frac{h_{1}-x}{\sqrt{r_{1}{ }^{2}-\left(x-h_{1}\right)^{2}}}\right)\right]_{x_{0}}^{x_{1}} \\
& \approx 132.387 \mathrm{ft}^{2} .
\end{aligned}
$$


Sections $A_{2}$ and $A_{3}$ were calculated in a similar fashion to (8) and (9). Their respective values were $A_{2} \approx 216.082 f t^{2}$ and $A_{3} \approx 231.191 f t^{2}$. Therefore the total area of this irregularly shaped room was

$$
A=A_{1}+A_{2}+A_{3} \approx 132.387+216.082+231.191=579.660 f t^{2} .
$$

\section{DISCUSSION}

After integrating these derived equations, the area was found to be around $580 f t^{2}$. This result seems plausible in light of a rough rectangular estimate of $30 \mathrm{ft} \times 20 \mathrm{ft}=600 \mathrm{ft}^{2}$. These results showed that precise computation is better than estimating as the rough estimate was $20 \mathrm{ft}^{2}$ over what was required. However in practice, a contractor would purchase a section of carpet with dimensions at least $30 \mathrm{ft} \times 22 \mathrm{ft}$ in order to carpet the entire floor in one piece. This follows from the facts that the longest dimensions of the room are $30 \mathrm{ft}$ and $22 \mathrm{ft}$ and that carpet is sold in rectangular pieces. If these dimensions were purchased, the contractor would be left with $80 f t^{2}$ of scrap carpet after each room.

\section{CONCLUSION AND RECOMMENDATIONS}

The area of this irregularly shaped room was determined by the summation of three integrals. By partitioning the room into separate sections, the overall calculation was simplified to summing areas bounded by semi-circles. Possible suggestions for future projects include calculating the area of a room with more than one irregularly shaped wall and calculating the volume of this room if it contained a vaulted ceiling. 


\section{APPENDIX}

\section{PoINTS AND SEGMENTS}

\begin{tabular}{|cc|}
\hline Name & Value (feet) \\
\hline$x_{0}$ & $(0.000,0.000)$ \\
\hline$x_{1}$ & $(6.443,0.000)$ \\
\hline$x_{2}$ & $(18.006,0.000)$ \\
\hline$x_{3}$ & $(29.250,0.000)$ \\
\hline$c_{1}$ & $(3.477,16.250)$ \\
\hline$c_{2}$ & $(11.836,26.527)$ \\
\hline$c_{3}$ & $(22.023,20.810)$ \\
\hline$r_{1}$ & 4.706 \\
\hline$r_{2}$ & 8.557 \\
\hline$r_{3}$ & 7.227 \\
\hline
\end{tabular}

\section{FUNCTIONS}

$\begin{array}{ccc}\text { Name } & \text { Value } & \text { Domain } \\ f_{1}(x)=(16.250)+\sqrt{(4.706)^{2}-(x-(3.477))^{2}}, & 0.000 \leq x \leq 6.443 \\ f_{2}(x)=(26.527)-\sqrt{(8.557)^{2}-(x-(11.836))^{2}}, & 6.443 \leq x \leq 18.006 \\ f_{3}(x)=(20.810)+\sqrt{(7.227)^{2}-(x-(22.023))^{2}}, & 18.006 \leq x \leq 29.250\end{array}$

\section{AREA OF RoOM}

$$
\begin{aligned}
\operatorname{Area}(\text { Room }) & =\int_{x_{0}}^{x_{1}} f_{1}(x) d x+\int_{x_{1}}^{x_{2}} f_{2}(x) d x+\int_{x_{2}}^{x_{3}} f_{3}(x) d x \\
& =(132.387)+(216.082)+(231.191) \\
& =579.66 f t^{2}
\end{aligned}
$$

